\title{
Heat Pipe based Thermal Management Systems for Energy-Efficient Data Centres
}

\author{
Hussam Jouhara $^{* 1}$, Richard Meskimmon ${ }^{2}$ \\ ${ }^{1}$ RCUK Centre for Sustainable Energy Use in Food Chains, College of Engineering, Design and \\ Physical Sciences, Brunel University, Uxbridge, Middlesex, UB8 3PH, UK, \\ Email: hussam.jouhara@brunel.ac.uk
}

${ }^{2}$ S \& P Coil Products Ltd, SPC House, Evington Valley Road, Leicester, LE5 5LU, UK

Submitted to

Energy

${ }^{*}$ Corresponding Author 


\begin{abstract}
This paper investigates the potential applications for heat-pipe based heat exchangers in enhancing the efficiency of data centres' cooling. The paper starts by assessing current industry practise and highlighting the challenges facing the data-storage industry; illustrating the legislative, technical and commercial constraints that are now, or will be prevalent in the industry as the sector continues to grow to cater for the ever increasing appetite for public sector, commercial and consumer remote data storage. The concept of free cooling and its potential application in data-centres is then introduced and analysed. A theoretical model is then constructed based on the established, proven performance characteristics of heat-pipe technologies and the weather data for a typical region in the UK. A case study has been conducted thereon and the results indicate potential energy savings of up to $75 \%$ are achievable when utilising heat pipe based free cooling systems.
\end{abstract}

\title{
1. INTRODUCTION
}

Climate change has established itself as the greatest driving force for innovation in the industry for the first time in over two centuries [1-4]. Therefore, vigorous research activities to reduce the energy consumption of energy-intensive establishments such as data centres are being carried out by researchers and engineers over the last 30 or so years.

Data-centres are facilities used to house IT systems and associated hardware, such as telecommunications and storage systems. It generally includes redundant or backup power supplies, redundant data communications connections, environmental controls (i.e. HVAC heating, ventilation \& air conditioning), fire suppression and security devices. Continuous growth in this sector, particularly in storage, network and computer capacities have resulted in increasing power density and heat dissipation in data-centres, thereby increasing the cooling needs and costs. The UK government is already making efforts to control this increase and promote energy efficiency through the Carbon Reduction Commitment (CRC) legislation, as part of the Climate Change Act 2008 [5]. This legislation's main purpose is a mandatory carbon reduction and energy efficiency scheme aimed at changing energy use behaviours and whilst it is not specifically aimed at data-centres by its definition data-centres will be significantly impacted.

The Green Grid, which a non-profit organization, identifies data-centre power and cooling as two of the biggest issues facing IT organisations today [6]; however it is not expected that data-centres will trade off resiliency or performance for energy efficiency due to their critical function and the increasing reliance on the internet. These centres require lots of flexibility, and will, for example, want to fit high density servers in any location around the world. Data-centres have been classified; the simplest being a Tier 1 data-centre and the most stringent being a Tier 4 data-centre, which would be designed to host mission critical computer systems. Further details are available in the TIA-942: Data-centre Standards Overview [7]. 
Current and planned legislation is also driving the need to find commercially viable alternatives for reducing or recovering the cost of cooling critical data storage infrastructure. Data storage service providers are faced with the challenge of developing storage technologies that generate less heat or finding the means to cool them that has lower net energy consumption.

In October 2008, the EU launched its Code of Conduct on Data-centres Energy Efficiency [8], which focuses on two areas. There were:

- IT Load - this relates to the consumption efficiency of the IT equipment in the datacentres,

- The Facilities Load - this relates to the mechanical and electrical systems that support the IT electrical load such as cooling systems.

This Code of Conduct states that electricity consumed in data-centres, including enterprise servers, ICT equipment, cooling equipment and power equipment, is expected to continue to contribute substantially to the electricity consumed in the European Union (EU). Western European electricity consumption for the sector of 104 TWh per year can be estimated for the year 2020. These projected energy consumption rises pose a problem for EU energy and environmental policies, it is therefore important that the energy efficiency of data-centres is maximised to ensure the carbon emissions and other impacts such as strain on infrastructure associated with increases in energy consumption are mitigated. The Code has already identified an increasing willingness of manufacturers and vendors to compete on the basis of energy efficiency in data-centres. It appears businesses are becoming increasingly aware of their environmental imperatives and the need to reduce energy consumption. However awareness does not necessarily lead to good decision making. The successful data-centre operators of the future will be aware of the financial, environmental and infrastructure benefits to be gained from improving the energy efficiency of their facilities through optimisation of power distribution, cooling infrastructure, IT equipment and IT output.

Based on the above, the thermal management of data-centres continues to be an expensive process, justified thus far because of the critical nature of such facilities. Increasingly high energy costs and the need for more efficient and sustainable cooling solutions will continue to be a top priority for engineers and planners. Taking the Silicon Valley in California as an example, the air conditioning of its data-centres is responsible for about $40 \%$ of its total energy consumption [9]. Other energy data from around the world report similar findings where these centres were found to consume many time higher than department stores, commercial buildings, and other high-energy consuming installations. Therefore, the utilisation of free cooling opportunities to reduce the energy cost and greenhouse gases emissions is a must-have if the climate conditions are suitable [10].

\subsection{Free cooling}

ASHRAE's Thermal Guidelines for Data Processing Environments [11] recommends a temperature range of $18-27^{\circ} \mathrm{C}$ for general operational areas. In order to successfully adopt a free cooling strategy the outside air will need to be at least $5^{\circ} \mathrm{C}$ cooler than that being 
maintained inside which imposes a limit on the applicability of these systems to temperate climates. Free cooling involves the replacement of 'warm' internal air with 'cool' outside air and is employed whenever the outside air is suitable for direct introduction into the data centre. Examples where free cooling is not appropriate are situations whereby the humidity of the outside air is not suitable or the contaminant level of outside air is high or there is a risk of smoke being drawn into the operating environment. In these instances indirect free cooling is appropriate whereby there is no air exchange just heat transfer via a heat exchanger.

Rather than conditioning the temperature of the entire data centre, contemporary techniques concentrate on the direct cooling of the server racks using hot or cold aisle containment. Such techniques involve the cooled supply air being delivered directly to the servers and the hot return air from the servers (typically around $36^{\circ} \mathrm{C}$ ) cooled back to the supply temperature. These elevated return temperatures open up the possibility to extend the range of outside conditions which are appropriate for free cooling.

The utilisation of spontaneous free cooling systems is proven to be feasible in cold to moderate-temperature climates where the ambient temperature is below the design temperature of the data-centre for most of the year. However, delayed free cooling is also possible with the increasing use of phase change materials (PCMs) to absorb the heat energy by melting the PCM material (latent heat), when the outside temperature values are not suitable for direct free cooling, and to release this heat energy when the outside ambient temperature drops to a low-enough value to secure the release of the absorbed latent heat and solidify the PCM within the heat exchanging system [12-15]. This storage capability, when coupled with a suitable heat exchanging system, can provide a free cooling solution even in desert-like climates, by utilising the wide day-night temperature difference.

In some cases, when free cooling solutions are considered, the pumping power that is needed to sustain the heat exchange process can prove costly and it can, in extreme cases, jeopardise the feasibility of the free cooling solution due to high running costs. This is the case when low temperature differences exist for most of the year between the data-centre return air and the ambient. Under such conditions, high flow rates of the hot and cold streams are required to secure the necessary heat transfer rate [16;17].

Taking the running cost of the heat exchangers into account, free cooling periods of datacentres can then be extended if this cost is lowered or even eliminated if passive cooling solutions, such as the heat pipe technology, are designed and adopted.

Based on the above and when the climate conditions allow for free cooling solutions, heat pipes, especially the gravity-assisted designs, are more economical than conventional system due to their passive operation, efficiency, reliability, and the relatively low cost of manufacturing when compared with conventional air cooling solutions that are used in datacentres. In addition, this technology provides an additional level of contingency, which helps in extending the intervals between regular maintenance schedules [18-22]. 


\subsection{Heat pipes}

Heat pipes have been utilised in small-scale electronics applications for decades for cooling critical microprocessor components [23;24]. The wicked heat pipe, which was developed in the 1960's by NASA for their aerospace and satellite needs has subsequently been universally adopted by the electronics industry [23]. These small-scale heat pipes, which work in any orientation or gravitational conditions to cater for the mobile nature of their usage, are massproduced globally and have become a highly commoditised manufacturing industry in their own right. The wicks in these heat pipe are required to enable the operation of the heat pipe at any orientation.

Gravity, instead of the wick, can be utilised in heat pipes to enable the return of the working fluid condensate back to the evaporator. These heat pipes are called wickless heat pipes. Wickless heat pipes, also known as gravity-assisted heat pipes, are hermetically sealed tubes containing a working fluid in both the liquid and vapour phases. They utilise the highly efficient thermal transport process of evaporation and condensation to transport heat from one end to the other where the heat can be dissipated through a heat sink. The amount of heat that can be transported by these devices is normally several orders of magnitude greater than pure conduction through a solid metal [19;25-32]. As this heat pipe configuration relies on gravity to return the condensate working fluid from the condenser to the evaporator, it must have an inclination of at least $5^{\circ}$ from the horizontal with the condenser above the evaporator.

With the two-phase cycle within the heat pipe, it is, therefore, possible to transfer a high rate of heat between the ends against an almost zero temperature difference internally along the length of the pipe while allowing a physical separation between the evaporator and the condenser [30]. For these reasons, the heat pipe is commonly known as a 'thermal superconductor' which only relies on a temperature difference for the working fluid to begin circulating and transferring heat, which means it is a totally passive device. In addition, this type of heat pipe relies on gravity and will only transfer heat in one direction giving it the properties of a "thermal diode" [31].

These combined properties of the heat pipe make it ideal for indirect free cooling applications. A myriad of individual heat pipes can be assembled together in a fin block in just the same way that a conventional heating/cooling coil or DX evaporator/condenser is assembled. The extended secondary surface area of the heat pipe heat exchanger then lends itself perfectly to its role in transferring heat between airstreams.

Figure 1 shows typical heat pipe heat exchanger blocks; note the many similarities to a conventional coil. Fabrication of heat pipes share many common features with conventional coil manufacture which means that the costs of these two items now of a similar order.

The heat pipes are likely to use a gravity return system arranged so that heat can only be transferred out of the building. Forced convection can be used on the heat exchangers to increase and to control the rate of heat transfer. The benefit of this solution therefore is that at times when the ambient temperature is below the return air temperature, a cooling heat transfer can be affected with a reduced energy requirement compared with conventional 
HVAC systems, without the requirement for external air to be brought into the building. The reported work examines the nature of data-centres to establish the applicability of this technique as well as the potential energy saving [19;21;22;29;33].

Scaling the heat pipe to cater for large, static installations has proven to be more challenging. Creating large-scale heat pipes by conventional manufacturing techniques has meant they were prohibitively expensive and uncompetitive in the HVAC industry. However, revolutionary manufacturing technologies are establishing static, gravity assisted heat pipes as the emerging challenger in difficult waste heat recovery applications such as those found in data server centres. The fact that waste heat can be reliably captured via an almost limitless range of heat-sink media has opened up the possibility to recover more of the heat drawn from large-scale data-centre sources and apply it in a wide variety of commercially useful applications such as air, water or thermal oil preheating for internal consumption or for export to district energy consumers [20;28].

This paper considers the benefits of the utilisation of the heat pipe technology in heat exchanging systems that fulfil part or all the cooling requirements of data-centre facilities. This technology will have its full potential in cold climates where $100 \%$ indirect free cooling of the data-centre can be achieved with no cross-contamination between the outside air and the conditioned air within the controlled space.

\subsubsection{Heat pipe heat exchanger applications in indirect free cooling}

Indirect free cooling relies on the use of cool outside air to absorb heat from warm return air and to hence provide a cooling effect.. The two airstreams are only indirectly in contact with one another via the heat pipes and there is no cross-contamination; the outside air which has absorbed heat from the return is extracted to the ambient. While indirect free cooling can never be as efficient as direct free cooling using outside air exchange, its benefits are associated with the recirculation of space air without the need for outside air intake [22;29].

For many applications, outside air intake is not acceptable as it can increase the space humidity, increasing the risk of cross-conduction and corrosion of components of the IT equipment. Outside air will also bring airborne contaminants with it unless effectively filtered and ducted inlet cannot preclude the ingress of smoke.

Figure 2 shows one possible schematic of an indirect free cooling unit incorporating a heat pipe. A DX evaporator coil is also shown inside the unit such that, if external conditions demand, the external condensing unit can be operated in order to provide conventional cooling against peak conditions. Alternatively the unit may contain a chilled water coil connected to an external air cooled chiller. A further enhancement of the equipment could see a direct cooling option being included which would allow outside air to directly cool the space if ambient conditions (humidity etc.) did not preclude its use. Depending on the climate into which the equipment was being fitted it could conceivably provide three different cooling regimes:

1. direct free cooling when the ambient temperature was sufficiently low and ambient contaminants and humidity at acceptable levels

2. indirect free cooling when the ambient temperature is low but ambient air quality poor 
3. active cooling when the ambient temperature was high.

The authors are responsible, either jointly or individually, for all work which has currently been undertaken regarding the use of heat pipes in indirect free cooling applications for data centres. The concept is still in its infancy but has been manifested in a number of incarnations into real time applications for a variety of service providers. The paper is an attempt to describe the virtues of such systems rather than give details of particular installations which would be to betray commercially sensitive knowledge and retard the movement towards a more widespread adoption of the application technology.

\section{CASE STUDY}

A typical effectiveness for a heat pipe heat exchanger in such a system is of the order of $50 \%$ i.e. it will provide cooling at a rate equal to $50 \%$ of that achieved with a direct cooling system handling the same air volume flow rates.

A heat pipe having 6 rows of tubes in the direction of airflow will provide an effectiveness of $50 \%$ and while greater effectiveness values can be achieved with deeper heat pipes there is a penalty in terms of the airside resistance. If the return air temperature is $36^{\circ} \mathrm{C}$ off the server racks and the outside air is at, say $20^{\circ} \mathrm{C}$ then an effectiveness of $50 \%$ will reduce the return air temperature by $8^{\circ} \mathrm{C}$ ( $50 \%$ of the total $16^{\circ} \mathrm{C}$ temperature difference) down to $28^{\circ} \mathrm{C}$.

The heat pipe itself is a passive device and requires no energy to operate other than the fan power that is required to move air around the system. The equivalent seasonal COP for a heat pipe system can be higher than 30 depending upon the temperatures involved and this compares to a value of around 3 for a conventional cooling system. These increased COPs would have a major influence on the reduction of a facility's PUE (power usage effectiveness), particularly in climates where the ambient air temperature is consistently lower than the temperature of the supply air. If the indirect cooling system is not able to generate the required delivery temperature (typically around $21^{\circ} \mathrm{C}$ ) then the active cooling system will need to provide the top up.

A significant benefit of the heat pipe indirect free cooling method is that it allows simultaneous operation of both the free cooling and active cooling elements i.e. the equipment can operate for many hours in partial free cooling mode unlike other systems which can operate either in active cooling mode or free cooling mode. There are significant energy saving benefits associated with partial free cooling mode compared to the either or scenario i.e. the free cooling can work alongside the active cooling when free cooling can provide some benefit but does not have the potential to provide $100 \%$ of the cooling required.

The following analysis is based upon a notional data-centre with a $100 \mathrm{~kW}$ IT load. It is assumed that it is conditioned using heat pipes in an indirect free cooling mode whenever the ambient air temperature is sufficiently low as to allow this mode of cooling to offset the full $100 \mathrm{~kW}$. At peak outside temperatures the active cooling takes up the slack while allowing the 
indirect free cooling to continue to provide whatever it is capable of. The equipment is assumed to be of the form shown in Figure 2.

The analysis presented below is based on bin data for a typical UK location and presents the annual outside temperature spread as a series of discrete temperature bins associated with the number of hours p.a. that the temperature falls within their limits. The bin data is ASHRAE historical data for a UK location at a latitude of $54.7^{\circ}$. It is assumed that the equipment is sized to handle a mass flow rate of $6 \mathrm{~kg} / \mathrm{s}$ of return air to provide the $100 \mathrm{~kW}$ of cooling. The same mass flow rate of air is assumed to be drawn across the external section of the heat pipe and that the inclusion of the heat pipe increases the total fan power requirements by $2 \mathrm{~kW}$.

The case study is necessarily general for the reasons outlined in the previous section. It is, however, scalable in that it will give a good approximation of the saving available for any size of system or data centre cooling load by a simple pro-rating of the savings based on the actual cooling load. The study is based on a notional cooling load of $100 \mathrm{~kW}$ to enable the scaling while it is understood that the majority of real time applications will have loads which are considerably higher

Table 1 shows the annual potential for the use of indirect free cooling using the heat pipe solution. The bottom line figure for this $100 \mathrm{~kW}$ cooling load is a net energy input to the cooling system saving of $75 \%$. Note that the input power saving is calculated as $1 / 3$ rd of the indirect cooling rate as it is assumed that the active cooling system will operate at a seasonal COP of 3. Figure 3 plots the potential for indirect free cooling across the range of annual outside air temperatures.

The adoption of the number of bins is arbitrary and the more bins then the greater the accuracy of the analysis. The use of 12-off bins is a compromise between accuracy and computational necessity so as to achieve a meaning quantification of the savings. The midpoint temperature is the mid range of the temperature bin and this temperature is adopted in the calculation of energy savings.

The nature of the data centre cooling systems investigated i.e. hot/cold aisle containment is such as to render the cooling load almost constant against the range of ambient temperatures. The aim is not to condition the entire data centre but to cool the server racks. The return air direct from the racks is being conditioned and this is assumed to be a constant 36 degrees and the cooling supply air direct to the racks is constant at 21 degrees. As a result the cooling load on the air conditioning equipment will be very nearly constant across the range of annual ambient temperatures. The variation in the ambient will only affect the available rate of indirect free cooling. Accordingly, the analysis assumes that the cooling load remains constant at $100 \mathrm{~kW}$ across the year.

The indirect cooling rate is based on the heat pipe at an effectiveness of $50 \%$ cooling the data centre air, the shortfall towards the required $100 \mathrm{~kW}$ is taken up by the active A/C system which could be via direct expansion equipment or indirectly via a chiller generating chilled water fed to a chilled water coil. 
The cooling system input power saving is calculated by dividing the indirect free cooling available by the COP of the active cooling system. The COP represents the rate of cooling divided by the electrical power input of the active cooling system and this is taken as being equal to 3 for typical UK operation.

The additional fan power is that power which is required to draw air across the heat pipe external surface and is in addition to the power required to draw air across the main cooling coil. This represents an additional power requirement which would not be manifest without the heat pipe indirect free cooling device. It is calculated by multiplying the air volumetric flowrate by the airside pressure drop associated with the heat pipe and assuming a combined efficiency of fan, drive and motor of $65 \%$.

The net power saving associated with the inclusion of the heat pipe device is the cooling system input power saving less the additional fan power requirement and the energy saving is equal to the power saving multiplied by the number of hours p.a represented by the particular bin.

This example is one of many that could have been taken and the results are very dependent upon the set of outside air conditions selected; in colder climates there would be potential for almost year round indirect free cooling without the need for active cooling other than for emergency use. The savings accrued by installing the indirect cooling device would allow owners to achieve payback returns of around 1 year based on the additional capital investment associated with the heat pipe system. Scaling of the savings based on the actual cooling load will show considerably reduced payback periods for larger scale data centres and the result are therefore considered to be conservative and representative of a worst case scenario for a UK climate.

When combined with the compact footprint of the heat pipe heat exchanger, the lack of moving parts and ease of maintenance the low initial capital expenditure ensures that heat pipes can provide the most suitable means of generating meaningful rates of indirect free cooling.

\section{CONCLUSIONS}

Building data-centres is a growing industry, often with high energy costs. The motivation of decision makers to consider energy cost as a priority is therefore fairly likely, in particular where companies are coming under scrutiny from government and environmental pressure groups. These groups will seek to influence their customer base to ensure taking the needed action to improve their sustainability.

A clear potential for the Heat Pipe Solution has been identified in this paper where around $75 \%$ of energy saving can be expected by utilising heat pipe based free cooling solutions. The heat pipe technology potential has been proven in HVAC systems where it is now being adopted widely. In order to take the development of this solution forward it is recommended 
that further research is done and partners with a detailed understanding of the data-centre market should be sought. This will allow an evaluation of the solution to establish its suitability to the market in detail.

\section{REFERENCES:}

[1] Olabi AG. The 3rd international conference on sustainable energy and environmental protection SEEP 2009 Guest Editor, Introduction. Energy 2010 Dec;35(12):4508-9.

[2] Olabi AG. Developments in sustainable energy and environmental protection. Simulation Modelling Practice and Theory 2011 Apr;19(4):1139-42.

[3] Olabi AG. Developments in sustainable energy and environmental protection. Energy 2012 Mar;39(1):2-5.

[4] Olabi AG. State of the art on renewable and sustainable energy. Energy 2013 Nov $1 ; 61(0): 2-5$.

[5] Climate Change Act . 2008. 7-5-0014.

[6] The Green Grid, Data Centre Power Efficiency White Paper 02 July 2008. www.thegreengrid.org. 2008.

[7] Data Center Standards Overview. Sited August-13 at www.adc.com.

[8] Code of Conduct on Data Centres Energy Efficiency 30 October 2008. Sited August13 at www.europa.eu.

[9] Lee KP, Chen HL. Analysis of energy saving potential of air-side free cooling for data centers in worldwide climate zones. Energy and Buildings 2013 Sep;64(0):103-12.

[10] Siriwardana J, Jayasekara S, Halgamuge SK. Potential of air-side economizers for data center cooling: A case study for key Australian cities. Applied Energy 2013 Apr;104(0):207-19.

[11] ASHRAE Thermal Guidelines for Data Processing Environments 2004. ISBN/ISSN 1-931862-43-5. 2004.

[12] Gui X, Tang D, Liang S, Lin B, Yuan X. Influence of void ratio on thermal performance of heat pipe receiver. International Journal of Heat and Fluid Flow 2012 Feb;33(1):109-17.

[13] Weng YC, Cho HP, Chang CC, Chen SL. Heat pipe with PCM for electronic cooling. Applied Energy 2011 May;88(5):1825-33. 
[14] Zalba B, Maron JM, Cabeza LF, Mehling H. Review on thermal energy storage with phase change: materials, heat transfer analysis and applications. Applied Thermal Engineering 2003 Feb;23(3):251-83.

[15] Nithyanandam K, Pitchumani R. Computational studies on a latent thermal energy storage system with integral heat pipes for concentrating solar power. Applied Energy 2013 Mar;103(0):400-15.

[16] Incorpera F.P., Dewitt D.P., 1, Bergman T.L., Lavine A.S. Fundamentals of Heat and Mass Transfer. 6th. 15-10-0010. Wiley Publishers.

[17] Anisimov S, Pandelidis D. Numerical study of the Maisotsenko cycle heat and mass exchanger. Int J Heat Mass Transfer 2014 Aug;75(0):75-96.

[18] Fadhl B, Wrobel LC, Jouhara H. Numerical modelling of the temperature distribution in a two-phase closed thermosyphon. Applied Thermal Engineering 2013 Oct 2;60(12):122-31.

[19] Jouhara H. Economic assessment of the benefits of wraparound heat pipes in ventilation processes for hot and humid climates. Int $\mathrm{J}$ Low-Carbon Tech 2009;4(1):52-60.

[20] Jouhara H, Anastasov V, Khamis I. Potential of heat pipe technology in nuclear seawater desalination. Desalination 2009;249(3):1055-61.

[21] Danielewicz J, Sayegh MA, Eniechowska B, Szulgowska-Zgrzywa M, Jouhara H. Experimental and Analytical Performance Investigation of Air to Air Two Phase Closed Thermosyphon based Heat Exchangers. Energy . 2014, DOI: 10.1016/j.energy.2014.04.107.

[22] Jouhara H, Meskimmon R. Experimental investigation of wraparound loop heat pipe heat exchanger used in energy efficient air handling units. Energy 2010 Dec;35(12):4592-9.

[23] Swanson TD, Birur GC. NASA thermal control technologies for robotic spacecraft. Applied Thermal Engineering 2003 Jun;23(9):1055-65.

[24] Yousefi T, Mousavi SA, Farahbakhsh B, Saghir MZ. Experimental investigation on the performance of CPU coolers: Effect of heat pipe inclination angle and the use of nanofluids. Microelectronics Reliability 2013 Dec;53(12):1954-61.

[25] Shabgard H, Xiao B, Faghri A, Gupta R, Weissman W. Thermal characteristics of a closed thermosyphon under various filling conditions. Int J Heat Mass Transfer 2014 Mar;70(0):91-102.

[26] Jouhara H, Robinson AJ. An experimental study of small-diameter wickless heat pipes operating in the temperature range $200^{\circ} \mathrm{C}$ to $450^{\circ} \mathrm{C}$. Heat Transfer Eng 2009;30(13):1041-8.

[27] Jouhara H, Robinson AJ. Experimental investigation of small diameter two-phase closed thermosyphons charged with water, FC-84, FC-77 and FC-3283. Applied Thermal Engineering 2010 Feb;30(2-3):201-11. 
[28] Khamis I, Jouhara H, Anastasov V. Heat pipes as an extra measure to eliminate radioactive contamination in nuclear seawater desalination. Desalination and Water Treatment 2010 Jan 13;13:82-7.

[29] Jouhara H, Merchant H. Experimental investigation of a thermosyphon based heat exchanger used in energy efficient air handling units. Energy 2012 Mar;39(1):82-9.

[30] Faghri A. Heat Pipe Science and Technology. Taylor \& Francis, 1995.

[31] Reay K, Kew P. Heat Pipes: Theory Design and Application. 5 ed. USA: ButterworthHeinemann., 2006.

[32] Dunn P, Reay D. Heat Pipes. 4 ed. Uk: Pergamon, 1976.

[33] Jouhara H, Ajji Z, Koudsi Y, Ezzuddin H, Mousa N. Experimental investigation of an inclined-condenser wickless heat pipe charged with water and an ethanolГÇôwater azeotropic mixture. Energy 2013 Nov 1;61(0):139-47. 
Table 1 Bin data energy analysis

\begin{tabular}{|c|c|c|c|c|c|c|c|c|c|c|c|c|}
\hline Bin no. & 1 & 2 & 3 & 4 & 5 & 6 & 7 & 8 & 9 & 10 & 11 & 12 \\
\hline Temperature range $\left({ }^{\circ} \mathrm{C}\right)$ & $\begin{array}{c}23.9 \\
\text { to } \\
26.7 \\
\end{array}$ & $\begin{array}{c}21.1 \\
\text { to } \\
23.9 \\
\end{array}$ & $\begin{array}{c}18.3 \\
\text { to } \\
21.1 \\
\end{array}$ & $\begin{array}{c}15.6 \\
\text { to } \\
18.3 \\
\end{array}$ & $\begin{array}{c}12.8 \text { to } \\
15.6\end{array}$ & $\begin{array}{c}10.0 \\
\text { to } \\
12.8 \\
\end{array}$ & $\begin{array}{c}7.2 \text { to } \\
10.0 \\
\end{array}$ & $\begin{array}{c}4.4 \\
\text { to } \\
7.2\end{array}$ & $\begin{array}{c}1.7 \\
\text { to } \\
4.4\end{array}$ & $\begin{array}{c}-1.1 \\
\text { to } 1.7 \\
\end{array}$ & $\begin{array}{l}-3.9 \\
\text { to }- \\
1.1\end{array}$ & $\begin{array}{l}-6.7 \\
\text { to }- \\
3.9\end{array}$ \\
\hline Mid-point temperature $\left({ }^{\circ} \mathrm{C}\right)$ & 25.3 & 22.5 & 19.7 & 17.0 & 14.2 & 11.4 & 8.6 & 5.8 & 3.1 & 0.3 & -2.5 & -5.3 \\
\hline Hours p.a. & 10 & 62 & 177 & 675 & 1144 & 1514 & 1770 & 1641 & 1124 & 555 & 80 & 8 \\
\hline Return air temperature $\left({ }^{\circ} \mathrm{C}\right)$ & 36.0 & 36.0 & 36.0 & 36.0 & 36.0 & 36.0 & 36.0 & 36.0 & 36.0 & 36.0 & 36.0 & 36.0 \\
\hline Total cooling load (kW) & 100.0 & 100.0 & 100.0 & 100.0 & 100.0 & 100.0 & 100.0 & $\begin{array}{c}100 . \\
0\end{array}$ & $\begin{array}{c}100 . \\
0\end{array}$ & 100.0 & 100.0 & 100.0 \\
\hline Return air flow rate $(\mathrm{kg} / \mathrm{s})$ & 6.00 & 6.00 & 6.00 & 6.00 & 6.00 & 6.00 & 6.00 & 6.00 & 6.00 & 6.00 & 6.00 & 6.00 \\
\hline $\begin{array}{l}\text { Indirect cooling outside air } \\
\text { flow rate }(\mathrm{kg} / \mathrm{s})\end{array}$ & 6.00 & 6.00 & 6.00 & 6.00 & 6.00 & 6.00 & 6.00 & 6.00 & 6.00 & 6.00 & 6.00 & 6.00 \\
\hline Heat pipe effectiveness (\%) & 50 & 50 & 50 & 50 & 50 & 50 & 50 & 50 & 50 & 50 & 50 & 50 \\
\hline $\begin{array}{l}\text { Indirect cooling rate } \\
\text { available }(\mathrm{kW})\end{array}$ & 32.1 & 40.5 & 48.9 & 57.0 & 65.4 & 73.8 & 82.2 & 90.6 & 98.7 & 100.0 & 100.0 & 100.0 \\
\hline $\begin{array}{l}\text { Active cooling required } \\
\text { (kW) }\end{array}$ & 67.9 & 59.5 & 51.1 & 43.0 & 34.6 & 26.2 & 17.8 & 9.4 & 1.3 & 0.0 & 0.0 & 0.0 \\
\hline $\begin{array}{l}\text { Cooling system gross input } \\
\text { power saving }(\mathrm{kW})\end{array}$ & 10.7 & 13.5 & 16.3 & 19.0 & 21.8 & 24.6 & 27.4 & 30.2 & 32.9 & 33.3 & 33.3 & 33.3 \\
\hline $\begin{array}{l}\text { Additional fan power } \\
\text { requirement (kW) }\end{array}$ & 2.0 & 2.0 & 2.0 & 2.0 & 2.0 & 2.0 & 2.0 & 2.0 & 2.0 & 2.0 & 2.0 & 2.0 \\
\hline $\begin{array}{l}\text { Net input cooling system } \\
\text { input power saving (kW) }\end{array}$ & 8.7 & 11.5 & 14.3 & 17.0 & 19.8 & 22.6 & 25.4 & 28.2 & 30.9 & 31.3 & 31.3 & 31.3 \\
\hline $\begin{array}{l}\text { Net cooling system energy } \\
\text { saving (kWh) }\end{array}$ & 87 & 713 & 2531 & 11475 & 22651 & 34216 & $\begin{array}{c}4495 \\
8\end{array}$ & $\begin{array}{c}4627 \\
6 \\
\end{array}$ & $\begin{array}{c}3473 \\
2 \\
\end{array}$ & $\begin{array}{c}1739 \\
0 \\
\end{array}$ & 2507 & 251 \\
\hline \multicolumn{7}{|c|}{ Total net cooling system energy saving (kWh) } & & & & & & \\
\hline \multicolumn{7}{|c|}{$\begin{array}{r}\text { Annual energy requirement w/o indirect free } \\
\text { cooling (kWh) }\end{array}$} & & & & & & \\
\hline \multicolumn{5}{|c|}{ Percentage saving (\%) } & \multicolumn{2}{|c|}{75} & & & & & & \\
\hline
\end{tabular}



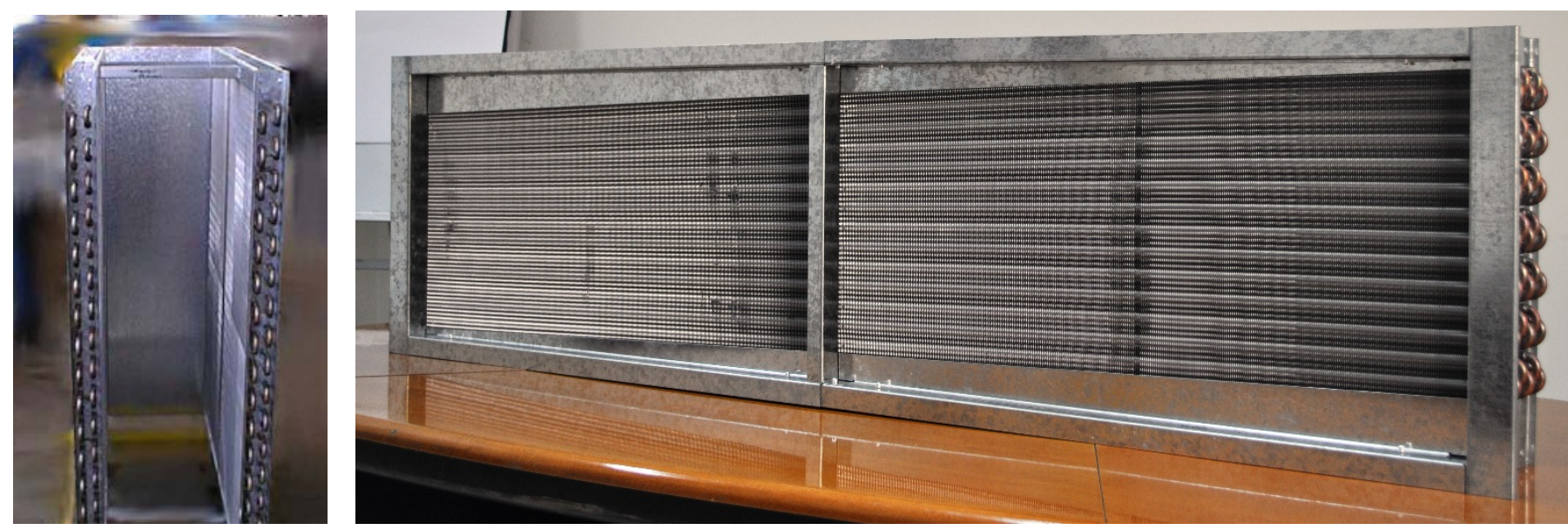

Figure 1 Typical heat pipe heat exchangers 


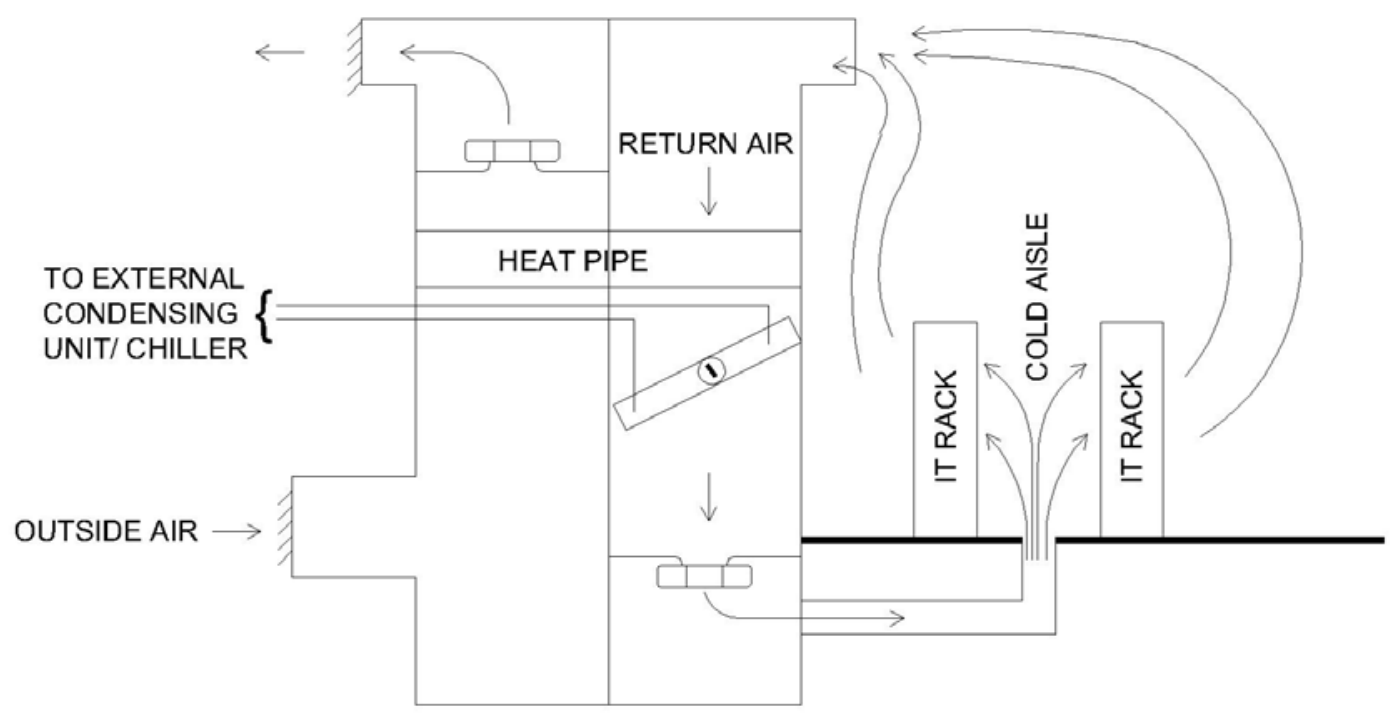

Figure 2 Arrangement of air conditioning unit 


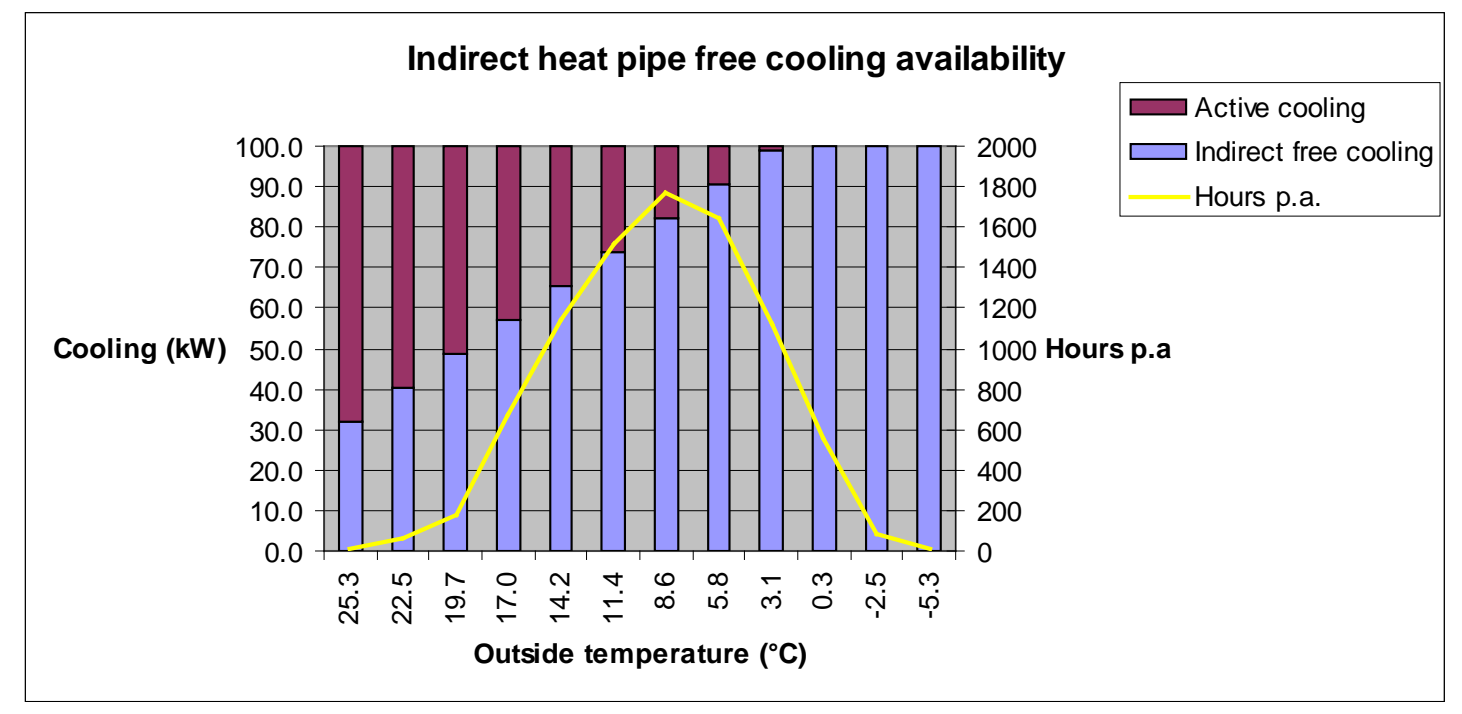

Figure 3 Free indirect cooling availability 